\title{
Species and space: role of volume in organizing coral reef fish assemblages in SE Cuba
}

\author{
Hari Balasubramanian ${ }^{1,2, *}$, Robert Stater Foster ${ }^{1}$ \\ ${ }^{1}$ Biodiversity Research Group, School of Geography and the Environment, University of Oxford, \\ Mansfield Road, Oxford OX1 3TB, UK \\ ${ }^{2}$ Present address: Conservation International, 2011 Crystal Drive, Suite 500, Arlington, Virginia 22202, USA
}

\begin{abstract}
A reliable species-area relationship holds true for a number of terrestrial systems. When species-area data are plotted on logarithmic axes, the slope bears strong consistency across taxa. This study examined effects of habitat space on the diversity of coral reef fish species. Because habitat space on coral reefs is 3-dimensional, we developed and employed a methodology that accounts for volume. A positive relationship was observed both between log species richness of fish and $\log$ area, and log species richness and log volume. Area explained 88 to $99 \%$ and volume explained 76 to $99 \%$ of the variation in species richness. The slopes of species-area curves observed here $(z=0.46$ to 0.61 ) are considerably higher than for other taxa (average $z$-value of 0.26 ), but are similar to those observed in other 3-dimensional systems (fishes 0.43 , carabid beetles 0.36 , birds 0.61 ). Volume accounted for some of the observed difference, and factoring out volume reduced the slope of the curve by up to $18 \%(z=0.38$ to 0.52$)$. An increase in suitable habitat (habitat diversity) has been proposed as an important factor explaining the noted increase in species relative to space. Habitat heterogeneity showed strong positive relationships with both area and volume. Canonical correspondence analysis indicated that habitat variables explained 66 to $76 \%$ of the variation in species richness at our sites at all spatial scales. The results of this study suggest that the relationship between species and space holds true for reef systems, and that habitat space and microhabitat diversity are good predictors of fish species richness.
\end{abstract}

KEY WORDS: Species-area $\cdot$ Species diversity $\cdot$ Marine conservation

\section{INTRODUCTION}

The contribution of spatial extent to species diversity and community structure has interested ecologists for the better part of the last century. In fact, the mathematical relationship that describes species richness as a function of area is one of the pillars of modern ecology (Arrhenius 1921, Gleason 1922, MacArthur \& Wilson 1967, Simberloff 1976, Connor \& McCoy 1979, Palmer \& White 1994, Rosenzweig 1995, Lomolino 2000, Chittaro 2002, Bellwood et al. 2005) and has been dubbed the 'most profound empirical observation in ecology' (Durrett \& Levin 1996). There has been considerable work on this specific question in terrestrial systems, yet comparatively fewer studies have considered the relationship between species richness and space as it relates to the marine realm (e.g. Bellwood \& Hughes 2001, Chittaro 2002). This relationship is of practical importance, especially in the light of managing areas for conservation; as the rate of habitat degradation increases, there is less suitable habitat available for native populations, thus creating 'habitat islands' (see Whittaker 1998). Further, the relationship is stronger for systems (terrestrial and aquatic) that occur in 3-dimensional space (i.e. bird communities, carabid beetles, fishes). As there appears to be a greater rate of increase in species richness relative to space in 3-dimensional systems, these are perhaps the most susceptible to the ravaging effects of habitat degradation. It has been noted that across all scales, 
increase in habitat area results in a greater number of species that can be supported (Rosenzweig 1995, 1999, Bellwood et al. 2005). This paper focuses on an improved understanding of this relationship - with special attention to volume - to help explain factors that organize species in 3-dimensional systems.

The consistent relationship between area and species number has been touted as one of ecology's few truths (May 1975). Although formally described by Arrhenius (1921) and modified by Gleason (1922, 1925), it has been documented since the middle of the 19th century (see Williams 1943). The logarithmic form of Gleason's equation is now almost exclusively used in ecology $[\log s=\log c+z \log a$ ] after its derivation in the 1960s (Preston 1960, 1962a,b). Various predictions have since been formulated that rely on these original mathematical approaches. Darlington (1957) hypothesized that for every 10 -fold decrease in the habitat of West Indian herpetofauna, the number of species decreases by half. More recently, ecologists have used species-area principles for protected area design (e.g. Diamond 1975) to support conservation prioritization (Brooks et al. 2002), and for predictions of global biodiversity loss (Pimm \& Raven 2000, Brooks et al. 2002). Understanding patterns of how species organize themselves in space will be invaluable for measuring marine biodiversity, identifying the number of species in reserves and, ultimately, developing marine conservation strategies (Neigel 2003).

Many hypotheses have been proposed to explain the species-area relationship. Among the most compelling is the 'equilibrium theory of island biogeography' (ETIB) (MacArthur \& Wilson 1967, Simberloff 1976). The ETIB propounds that species richness on an island is governed by distance from the source pool (chance of being colonized by new, different recruits) and the island's size (ability to support different species). If islands are a similar distance from the source pool, then larger islands will have lower extinction rates, higher immigration rates, and therefore more species present (Simberloff 1976). The main factors contributing to this trend act on an evolutionary level - speciation, extinction, emigration and immigration (MacArthur \& Wilson 1967). Similar processes work on a continental scale, and for habitat islands within continents (Rosenzweig 1995, Willis \& Whittaker 2002). A second explanation, 'the random placement' hypothesis, contends that more species are randomly sampled as area increases - an artefact of sample size (Hart \& Horwitz 1991). The increase in species encountered is considered purely random (Roberts \& Ormond 1987). A third explanation is the 'habitat-diversity' hypothesis. This theory suggests that microhabitat diversity increases as area increases. The rationale is that increased habitat diversity allows more ecological niches, and therefore the potential for more species to colonize the area under consideration (Connor \& McCoy 1979, Palmer \& White 1994, Bellwood et al. 2005).

Past studies of aquatic species-area relationships found $z$-values (i.e. the increase in the number of species relative to area) that were higher than typical 2-dimensional terrestrial studies (Angermeier \& Schlosser 1989, Chittaro 2002). Chittaro (2002) calculated $z$-values between 0.38 and 0.52 -i.e. higher than Preston's average across taxa of 0.26 (Preston 1962a,b, supported by May 1975). One explanation for the species-area relationship is that as area increases there is an increase in suitable habitat space, allowing more niches to be exploited by different species (Connor \& McCoy 1979, Palmer \& White 1994). For most specieshabitat space models, a 2-dimensional (aerial) plot is sufficient because terrestrial organisms are generally restricted to this planar component of space. The relationship with some taxa, such as birds, is better explained by a 3-dimensional plot (Nilsson et al. 1988, Chittaro 2002). Furthermore, analysis of species-area relationships for fishes and carabid beetles have yielded results not characteristic of terrestrial species considered in 2-dimensional space ( $z=0.43$ and 0.36 ) (Nilsson et al. 1988, Chittaro 2002). We contend that area is only an appropriate spatial parameter for some taxa. Although the mechanisms that drive speciesarea relationships may be similar, analyses of systems modeled in 3-dimensional space are more powerful if they consider volume. This study addressed a gap in current research by examining volume in speciesspace relationships (Angermeier \& Schlosser 1989, Chittaro 2002).

The topography of scleractinian coral and other substrates provides a multitude of habitat niches. As such, the 3-dimensional nature of tropical coral reef systems warrants a novel approach to species-area analyses. Prior to this study there was no methodological example of how to account for habitat volume in these systems. We proposed and utilized rugosity as an appropriate measure of this dimension of habitat space. The aims of this study were to (1) use rugosity as a metric to explore volume in species-area relationships for reef fishes in SE Cuba, and (2) explore the habitat-diversity hypothesis by testing the effects of various habitat attributes on these relationships.

\section{MATERIALS AND METHODS}

Field work was conducted from June 27 to August 7 , 2004 in the near shore waters of SE Cuba, $20 \mathrm{~km}$ from the city of Santiago de Cuba (Fig. 1). During this period, 10 patch reefs were randomly selected from 2 


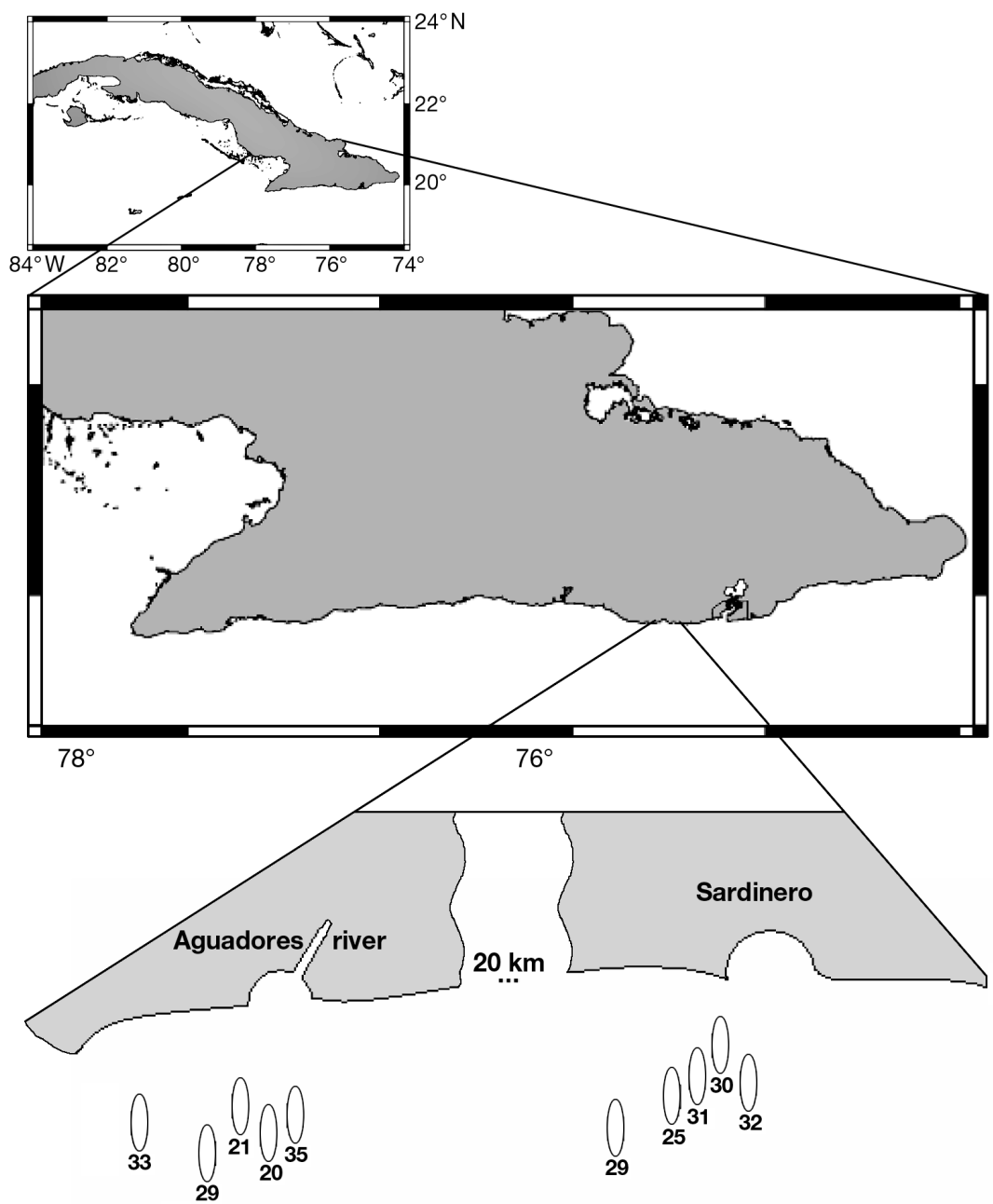

Fig. 1. Study area, near city of Santiago de Cuba. Orals represent surveyed patch reefs, and patch numbers correspond to those in Table 1

north to south. There was no substantial difference in depth among individual patches. Data were recorded by following a $20 \mathrm{~m}$ polyvinyl chloride (PVC) measuring tape laid above the contour of the substratum. Transects had a width of $5 \mathrm{~m}$, resulting in a total area of $100 \mathrm{~m}^{2}$ for each patch. Within each $100 \mathrm{~m}^{2}, 16$ survey stations were sampled, whereby the observer remained for $4 \mathrm{~min}$ at each station. Each survey station was $2.5 \mathrm{~m}$ long, $2.5 \mathrm{~m}$ wide and $5 \mathrm{~m}$ in height. Stations were located on either side of the PVC transect (Survey Stn 1 running from 0 to $2.5 \mathrm{~m}$ on the right, to Survey Stn 16 running from 17.5 to $20 \mathrm{~m}$ on the left).

The observer recording fish data was immediately followed at a distance of $\sim 7.5 \mathrm{~m}$ by a second observer, who recorded substrate characteristics along the transect line. The substrate was recorded at $1 \mathrm{~cm}$ intervals and categorized into 17 types, including coral (designated as living or dead), taxa of sessile invertebrates, algae, and substrates such as sand, rock, and rubble (small, medium or large). The relative abundance of each category was determined for each transect and analyzed as percent cover (cumulative microhabitat type distance/total transect distance $\times 100)$.

Topographic complexity (rugosity) was recorded for each transect as an index of substrate complexity. It was

sites (5 patches at each site): Sardinero, which is located within a marine protected area (Siboney-Juticí Biological Reserve), and Aguadores, which is located just outside the protected area. Patch reefs were defined as isolated structures surrounded by $\geq 2 \mathrm{~m}$ of non-reef habitat. All patches were chosen from a set with defined characteristics, comprising patch length between 30 and $60 \mathrm{~m}$, patch width between 10 and $25 \mathrm{~m}$, and depth between 7 and $13 \mathrm{~m}$. Transects ran parallel to each other, from north to south.

Different researchers documented fish and substrate data for each transect. Data on site characteristics were recorded for each day of the survey. Sampling was alternated between sites every day. Typically, 2 surveys were conducted each morning, the first between 06:00 and 07:00 $\mathrm{h}$, the second between 09:30 and 11:00 $\mathrm{h}$.

For each transect, fish diversity and abundance were recorded in 4 min blocks at 16 locations along a $20 \mathrm{~m}$ transect perpendicular to the shore. This direction was chosen because patches in the region were oriented determined as the ratio between a leaded, $20 \mathrm{~m}$-long nylon line fitted along the contour of the substratum and the linear distance over this contour (the distance of the transect line). Rugosity was recorded at 5, 10, 15 and $20 \mathrm{~m}$ along each transect. A value of 1 indicated that the substrate was planar, while increasing values indicated increasing topographical complexity.

All fish and substrate data were tested for normality using the Komogorov-Smirnov test in SPSS (Dytham 2003). The analysis was divided into 3 categories: species-area; species-volume; species-habitat.

Species-area. The $\log _{10}$ species vs. $\log _{10}$ area form of Preston's equation is widely recognized as best describing the data for species-area relationships (Preston $1962 \mathrm{a}, \mathrm{b})$. Therefore, for all sites, species richness was plotted against area using this transformation.

Data were organized as means at each site before generating species-area curves. Through random number generation, groups of plots of varying sizes were identified within the $100 \mathrm{~m}^{2}$ transects at each site: 
5 plots each were generated for the 6.25 and $12.5 \mathrm{~m}^{2}$ size classes, 4 plots for the $25 \mathrm{~m}^{2}, 2$ plots for the $50 \mathrm{~m}^{2}$, and 1 plot for the $100 \mathrm{~m}^{2}$ size class. Within each size class, no plot overlapped with any other plot, although some were adjacent. All regressions used 5 data points.

Species-volume analysis. Three-dimensional habitat space was calculated by multiplying reef area by the ratio of rugosity, $\mathrm{R}(\mathrm{R}=$ distance covered by leaded line/planar distance). Species-volume relationships were then transformed and analyzed in the same way as species-area relationships.

Microhabitat-space analysis. Microhabitat categories were plotted against area and volume at both sites. Methodology and analysis followed the same rationale as the species-area and species-volume methods described above.

Using non-metric multidimensional scaling (NMDS), it was established that the sites differed in species and habitat composition. Canonical correspondence analysis (CCA) was then used to compare habitat variables and total fish species richness within each site (ter Braak 1987). CCA analyses were conducted for cumulative data from all transects at each site $\left(100 \mathrm{~m}^{2}\right)$, as well as from several smaller spatial scales $\left(6.25,12.5\right.$ and $\left.25 \mathrm{~m}^{2}\right)$ (Henderson \& Seaby 1999). CCA forms a linear relationship for each fish and habitat data set and compares these in such a way that the greatest amount of variation is explained (factor 1 - the $x$-axis). It then repeats the process, keeping each factor independent of all others, to explain other sources of variation (Factor 2, Factor 3, etc., represented by the $y$-axis, $z$-axis, etc.) (ter Braak 1987). Typically, factor 1 and/or factor 2 variation will partition data sets if there is sufficient variation between them (Chittaro 2002). Habitat data were calculated as percentage cover and were therefore angular transformed before CCA analysis to improve normality (arcsine squareroot transformed) (Dytham 2003).

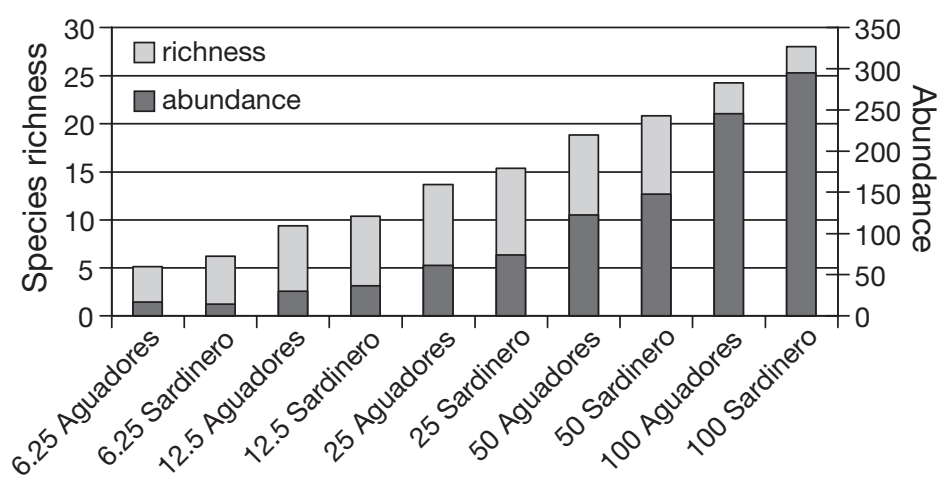

Site and area $\left(\mathrm{m}^{2}\right)$

Fig. 2. Average species richness and abundance of fishes for all spatial scales at both sites, Aguadores and Sardinero

\section{RESULTS}

Approximately $1 \mathrm{~km}^{2}$ of patch reef was censused during the data collection period in the summer of 2004. A total of 4939 individuals, belonging to 61 species, were recorded. Richness and abundance varied across spatial scales, with both being generally higher at Sardinero (Fig. 2).

\section{Species-area and species-volume}

Simple regressions for the $\log _{10}$ species and $\log _{10}$ area, and the $\log _{10}$ species and $\log _{10}$ volume plots showed strong positive relationships (Table 1), with $z$-values ranging from 0.4572 to 0.6094 for $\log _{10}$ species and $\log _{10}$ area curves, and from 0.3843 to 0.524 for $\log _{10}$ species and $\log _{10}$ volume curves at both sites.

\section{Microhabitat-space}

Microhabitat richness showed strong positive relationships with area at both sites. At Aguadores, the model with the highest coefficient of determination was the $\log _{10}$ richness- $\log _{10}$ area plot $\left(r^{2}=0.513\right)$. At Sardinero, the $\log _{10}$ richness- $\log _{10}$ area plot had a slightly lower $r^{2}$ than the richness- $\log _{10}$ area plot $\left(\mathrm{r}^{2}=0.728\right.$ and 0.736 , respectively). Microhabitat richness also showed a strong positive relationship with volume. The highest coefficient of determination at both sites was the $\log _{10}$ richness- $\log _{10}$ area plot, with $r^{2}=0.429$ at Aguadores and $r^{2}=0.646$ at Sardinero.

Canonical correspondence analysis for full transects showed that in Aguadores the first and second canonical axes explained 45.48 and $28.52 \%$ of the variation in diversity and abundance in fish assemblages, respectively $(99.87 \%$ total, Kendall's tau = 0.9184), and in Sardinero the first and second axes explained 37.45 and $29.1 \%$ of the variation, respectively $(99.28 \%$ total, Kendall's tau $=$ 0.9493). The environmental variables primarily responsible for this variation in Aguadores were: rubble/nutrient indicator algae (NIA), hard coral, old dead coral and old dead coral/NIA along Axis 1, and rubble, rock and zoanthid along Axis 2. At Sardinero rubble/ NIA, silt and sponge primarily explained the variance on Axis 1, while on Axis 2 sand/NIA, sand and NIA were important. CCA results from differing grain sizes showed some consistent patterns. After corrections for multicollinearity at Aguadores, sponge, other (Axis 1) and old dead coral/NIA (Axis 2) seemed to 
Table 1. Summary of linear regression models for species area and species volume relationships at both sites. Site numbers as in Fig. 1. All regressions were statistically significant at $\mathrm{p}<0.01 . \mathrm{z}$ : slope of regression. $\mathrm{T}$ : total

\begin{tabular}{|c|c|c|c|c|c|c|c|c|c|c|}
\hline \multirow[t]{2}{*}{ Site } & & \multirow[b]{2}{*}{$6.25 \mathrm{~m}^{2}$} & \multicolumn{3}{|c|}{ No. of replicates for plots of: } & \multirow[b]{2}{*}{$100 \mathrm{~m}^{2}$} & \multicolumn{2}{|c|}{ Area } & \multirow[b]{2}{*}{$z$} & \multirow{2}{*}{$\operatorname{Vol} \frac{}{r^{2}}$} \\
\hline & & & $12.5 \mathrm{~m}^{2}$ & $25 \mathrm{~m}^{2}$ & $50 \mathrm{~m}^{2}$ & & z & $\mathrm{r}^{2}$ & & \\
\hline \multirow[t]{5}{*}{ Sardinero } & 23 & 5 & 5 & 4 & 2 & 1 & 0.571 & 0.980 & 0.489 & 0.992 \\
\hline & 25 & 5 & 5 & 4 & 2 & 1 & 0.522 & 0.994 & 0.503 & 0.991 \\
\hline & 30 & 5 & 5 & 4 & 2 & 1 & 0.512 & 0.974 & 0.399 & 0.991 \\
\hline & 31 & 5 & 5 & 4 & 2 & 1 & 0.457 & 0.992 & 0.487 & 0.993 \\
\hline & 32 & 5 & 5 & 4 & 2 & 1 & 0.609 & 0.965 & 0.504 & 0.996 \\
\hline Grouped & $\mathrm{T}$ & 25 & 25 & 20 & 10 & 5 & 0.532 & 0.880 & 0.447 & 0.757 \\
\hline \multirow[t]{5}{*}{ Aguadores } & 21 & 5 & 5 & 4 & 2 & 1 & 0.552 & 0.973 & 0.494 & 0.995 \\
\hline & 28 & 5 & 5 & 4 & 2 & 1 & 0.474 & 0.949 & 0.393 & 0.960 \\
\hline & 29 & 5 & 5 & 4 & 2 & 1 & 0.607 & 0.968 & 0.524 & 0.982 \\
\hline & 33 & 5 & 5 & 4 & 2 & 1 & 0.522 & 0.952 & 0.384 & 0.999 \\
\hline & 35 & 5 & 5 & 4 & 2 & 1 & 0.583 & 0.986 & 0.497 & 0.999 \\
\hline Grouped & $\mathrm{T}$ & 25 & 25 & 20 & 10 & 5 & 0.543 & 0.909 & 0.442 & 0.845 \\
\hline
\end{tabular}

best explain the variation in species composition at smaller spatial scales $\left(6.25\right.$ and $12.5 \mathrm{~m}^{2}$, tau $=0.6244$ and 0.4615 , respectively, $\mathrm{n}=25$ ). Specific habitat categories at Sardinero failed to explain variation with the same strength. Nonetheless, old dead coral/ NIA (Axis 1) and recently dead coral (Axis 2) were consistent at small spatial scales $\left(6.25\right.$ and $12.5 \mathrm{~m}^{2}$, tau = 0.3962 and $0.4858, \mathrm{n}=25$ ). However, there were several conflicting results for different grain sizes, and it should be noted that there was very high multicollinearity for larger grain sizes - probably caused by the low number of samples for these sizes (Table 2).

\section{DISCUSSION}

Past studies have found the power function model $\left(\log _{10}\right.$ species richness and $\log _{10}$ area) to best represent the species-area relationship across taxa (Preston 1962a,b, Neigel 2003). The $z$-values obtained in the present study were somewhat higher than Preston's (1962a,b) 0.26 average across terrestrial taxa. Recent work supports Preston's $(1962 \mathrm{a}, \mathrm{b})$ findings for terrestrial plant communities $(z=0.19$ to 0.29 ) (Nilsson et al. 1988, Singh et al. 1996); $z$-values in this study ranged from 0.46 to 0.61 (mean at Sardinero =

Table 2. Summary of CCA analyses of habitat variables and their effect on fish species richness and abundance at different spatial scales. NIA: nutrient indicator algae; Kendall's tau: rank correlation of species/environment scores; All: all spatial scales combined

\begin{tabular}{|c|c|c|c|c|c|c|}
\hline \multirow{2}{*}{$\begin{array}{l}\text { Site/grain } \\
\text { size }\left(\mathrm{m}^{2}\right)\end{array}$} & \multicolumn{2}{|c|}{$\%$ variance explained } & \multirow{2}{*}{$\begin{array}{l}\text { Total \% variance } \\
\text { explained }\end{array}$} & \multicolumn{2}{|c|}{ Primary habitats responsible } & \multirow{2}{*}{$\begin{array}{c}\text { Kendal's tau } \\
\text { (Axis 1/Axis 2) }\end{array}$} \\
\hline & Axis 1 & Axis 2 & & Axis 1 & Axis 2 & \\
\hline \multicolumn{7}{|l|}{ Aguadores } \\
\hline 6.25 & 12.88 & 6.821 & 28.36 & Sponge, other & NIA, old dead coral/NIA & $0.6244 / 0.5509$ \\
\hline 12.5 & 5.505 & 4.174 & 11.41 & Sponge, other & Old dead coral/NIA & $0.4615 / 0.3987$ \\
\hline 25 & 29.55 & 19.73 & 70.68 & $\begin{array}{l}\text { Hard coral, old dead } \\
\text { coral/NIA, zoanthid }\end{array}$ & Rock, rubble, other & $0.6596 / 0.649$ \\
\hline All & 45.48 & 28.52 & 97.87 & $\begin{array}{c}\text { Rubble/NIA, hard coral, } \\
\text { old dead coral, } \\
\text { old dead coral/NIA }\end{array}$ & $\begin{array}{l}\text { Zoanthid, rubble, } \\
\text { rock }\end{array}$ & $0.9184 / 0.8562$ \\
\hline \multicolumn{7}{|l|}{ Sardinero } \\
\hline 6.25 & 10.24 & 4.642 & 19.46 & $\begin{array}{c}\text { Rubble/NIA, old dead } \\
\text { coral/NIA }\end{array}$ & $\begin{array}{c}\text { Sand/NIA, recently } \\
\text { dead coral }\end{array}$ & $0.3962 / 0.6279$ \\
\hline 12.5 & 8.459 & 6.219 & 26.7 & $\begin{array}{l}\text { Sponge, old dead coral, } \\
\text { old dead coral/NIA }\end{array}$ & $\begin{array}{l}\text { Silt, recently } \\
\text { dead coral }\end{array}$ & $0.4858 / 0.5676$ \\
\hline 25 & 116.1 & 32.29 & 215.7 & Old dead coral/NIA, sand, silt & Hard coral, NIA, rock & $0.528 / 0.3474$ \\
\hline All & 37.45 & 29.1 & 99.28 & Rubble/NIA, silt, sponge & Sand/NIA, sand, rock, NIA & $0.9493 / 0.9593$ \\
\hline
\end{tabular}


0.53, mean at Aguadores $=0.54$ ). Although higher than Preston's (1962a,b) findings, these values are consistent with species-area relationships observed for invertebrate groups ( $z=0.29$ to 0.48 ) (Nilsson et al. 1988 for carabid beetles, Peake \& Quinn 1993 for intertidal mussel clumps), bird communities $(z=$ 0.616) (Nilsson et al. 1988), and coral reef fishes ( $z=$ 0.38 to 0.52 ) (Chittaro 2002). All these examples also exist in 3-dimensional space, yet the relationships explored were restricted to 2-dimensional analysis. In the present study, $z$-values were reduced by up to $18 \%$ when volume was considered in the analysis (from 0.532 to 0.447 for Sardinero; and, from 0.543 to 0.442 for Aguadores).

We offer 5 explanations for the higher $z$-values observed in this study of coral reef fishes compared to those of past studies examining other systems: (1) the small range of spatial scales examined; (2) nested replicates within a given patch; (3) occurrence of frequent disturbance events on coral reefs in this area; (4) influence of the 3-dimensional nature of reef systems; and/or (5) greater habitat richness, leading to the accommodation of more species. These are considered below.

\section{Range of spatial scales examined}

An explanation for the high slope of the speciesarea curve could be the small range of areas sampled (Angermeier \& Schlosser 1989). As shown by Lomolino (2000), different patterns and processes drive the species-area relationship at different spatial scales. At the smallest scale, idiosyncratic differences between patches (islands) are especially important in driving species richness. Reef patches can be considered as islands because they are isolated structures with strongly associated organisms and instances of interchange between them. Area may be a poor predictor of species richness at this scale. Once the ecological threshold is reached, however, a relative increase in suitable habitat availability may provide a better explanation for a sharp increase in species richness. At some point, the effect of deterministic factors (such as space) on species richness lessens, and an asymptote of species richness is reached. Gradual increases in species richness are driven primarily by evolutionary processes (in situ speciation) once the evolutionary threshold has been reached (Lomolino 2000).

Other studies have examined the species-area relationship over broad spatial scales, up to several thousand square kilometers (Preston 1962a,b, Rosenzweig 1995). Our study was limited to a maximum of $100 \mathrm{~m}^{2}$ and a minimum of $6.25 \mathrm{~m}^{2}$. At relatively small spatial scales in regions with high habitat diversity, an increase in area may result in more available habitats. The increase in the number of habitats, however, cannot proceed indefinitely. One possible explanation for the high $z$-values we observed is that the patches were larger than the ecological threshold, allowing area to influence richness, but did not occupy a sufficiently large area to constitute asymptotic species richness; i.e. they fit on the steep part of the slope between $T_{\mathrm{i}}$ (the ecological threshold) and $T_{\mathrm{ii}}$ (the evolutionary threshold) (see Lomolino \& Weiser 2001).

\section{Nested patches}

Spatially based sampling protocol typically reveals spatial dependence (Palmer \& White 1994). Sampling stations near each other are more likely to be similar than more distantly spaced stations (Palmer \& Dixon 1990). The nested pattern of sampling plots used in this analysis introduces a further dependence: the data comprising one grain contribute to the data in each of the successive, larger grains. Palmer \& White (1994) found that the rate of species gain is much higher in non-nested than in nested quadrats. That is, the $z$ value of species-area curves for their plant species was higher in their analysis of non-nested quadrats than in their analysis of nested quadrats.

The area of the sampling plots was small in this study. This could have caused problems of spatial autocorrelation (Lichstein et al. 2002). The effect of autocorrelation, however, should result in an analysis that concurs with the observations of Palmer \& White (1994), i.e. higher $z$-values for non-nested than for nested sampling stations. This implies that the $z$-values in the present study may be an underestimate rather than an overestimate. If this is the case, our results are consistent with those of other studies examining species that rely on 3-dimensional space, e.g. a $z$-value of 0.616 for bird communities (Nilsson et al. 1988). This emphasises the importance of grain size in sampling coral reef systems. As recommended by Sale (1998), we should continue to design studies (with sufficient power) at scales relative to coral reef fish populations.

\section{Disturbance}

The reefs of SE Cuba are subjected to frequent tropical storms, which increase sedimentation levels and affect topographical complexity between the months of August and October. Although natural disturbances have been occurring for millions of years, recent history has seen a dramatic increase in anthropogenic pressures (Jackson et al. 2001). Spear-fishing and pollution are the primary human activities that affect the 
reefs in the present study. Both these activities contribute to changes in habitat diversity and structural complexity of the reef. Spear-fishing changes the topography of benthic structures by chipping away pieces of reef and rock, resulting in an increasing amount of rubble. Higher levels of phosphates and nitrates associated with effluent and run-off cause algal blooms and an increase in zoanthid and sponge biomass (Edinger et al. 1998). The synergistic effects of these disturbances are probably altering the species composition of these reefs, and may partially explain the high $z$-values obtained.

\section{Volume and increased habitat richness}

An extension of the habitat-diversity hypothesis (one particularly relevant to the marine realm) is the consideration of volume. As coral reefs are 3-dimensional systems, habitat changes over linear distance are greater than in 2-dimensional systems. Angermeier \& Schlosser (1989) found volume better than area for predicting fish species richness in streams. Chittaro (2002) also suggested volume as a partial explanation of the high $z$-values obtained in his study, but did not include volume in his analysis.

The habitat-diversity hypothesis propounds that increases in area result in an increased number of habitats, which in turn results in increased species richness (Connor \& McCoy 1979). Rosenzweig (1995) supported this hypothesis, noting that habitat richness is likely to play an important role in determining the number of species present, as an increased number of habitats offer more suitable niches for colonization. According to this hypothesis, a greater habitat richness per unit area should result in a steeper slope in the species-space curve (Roth 1976). Indeed, the log habitat richness and log space results of the present study indicate a positive relationship between habitat richness and space. This relationship is in accordance with the increase in species richness with increasing space. Further, consideration of previous marine species-area studies shows that habitat category diversity is correlated with higher $z$-values ( $z$-value of 0.24 for patches with 4 to 5 habitat categories, compared to $z$-values averaging 0.43 for patches with 15 categories at continuous reef sites - similar to the number of habitat categories observed in the present study) (Chittaro 2002). CCA plots support the habitat heterogeneity hypothesis, and showed that habitat accounted for a large proportion of the variation in species richness and abundance at our sites. Habitat heterogeneity, and its variation as a function of space, seems to be a good indicator of fish species richness in coral reef systems.

\section{CONCLUSION}

Although species extinction is one of the necessary processes of evolution, never before has it occurred at such an alarmingly fast rate (Whittaker 1998, Pimm \& Raven 2000). One of the major drivers of this trend at all spatial scales is habitat fragmentation and a decrease in the area of viable natural habitats (Whitmore \& Sayer 1992). The persistence of any species depends to at least some degree on the amount of space it occupies. Understanding this relationship is becoming exceedingly important in marine ecology in general and conservation in particular (Brooks et al. 2002). Although the species-area relationship has been explored extensively for 2-dimensional terrestrial realms, there is a paucity of such research in 3-dimensional and, particularly, marine systems.

This study found that species richness of coral reef fishes in SE Cuba is positively related to space (area and volume) for all sites surveyed. Our analysis of both the role of volume and that of habitat heterogeneity on the organization of fish species communities, supports the habitat-diversity hypothesis. Our results are consistent with other species-area relationships observed in marine systems (Chittaro 2002) and with speciesarea relationships observed in 3-dimensional systems. The slope of the species-space curve for marine systems is considerably higher than that for terrestrial studies. Several potential reasons have been suggested. We agree with Chittaro (2002) that terrestrial hypotheses seeking to explain this phenomenon (e.g. the random-placement and habitat-diversity hypotheses) should be examined in greater detail as to their suitability for marine systems. Our analysis, including volume, produced rather different $z$-values than previous studies. Understanding the relationship between reef fish diversity and space is vital for the conservation of many rapidly eroding coral-reef ecosystems. Further research exploring the role of volume in species organization in these systems is essential.

Acknowledgements. Special thanks to Drs. R. Ladle and T. P. Dawson for their support during this project. The authors also thank the Cuban research team at Bioeco and the SiboneyJuticí Biological Reserve in Santiago de Cuba. The manuscript was greatly improved after review by Dr. D. Bellwood and Dr. T. Brooks. Research was supported by the Ralph Brown Expedition Award to H.B. and R.S.F., by the Royal Geographical Society with the Institute of British Geographers (RGS with IGB), and by the Oxford University Expeditions Council.

\section{LITERATURE CITED}

Angermeier PL, Schlosser IJ (1989) Species area relationship for stream fishes. Ecology 70:1450-1462

Arrhenius O (1921) Species and area. J Ecol 37:260-274 
Bellwood DR, Hughes TP (2001) Regional-scale assembly rules and biodiversity of coral reefs. Science 292: 1532-1534

Bellwood DR, Hughes TP, Connolly SR, Tanner J (2005) Environmental and geometrical constraints on Indo-Pacific coral reef biodiversity. Ecol Lett 8:643-651

Brooks TM, Mittermeier RA, Mittermeier CG, Da Fonseca GAB and 7 others (2002) Habitat loss and extinction in the hotspots of biodiversity. Conserv Biol 16:909-923

Chittaro PM (2002) Species-area relationships for coral reef fish assemblages of St. Croix, US Virgin Islands. Mar Ecol Prog Ser 233:253-261

Connor EF, McCoy ED (1979) The statistics and biology of the species-area relationship. Am Nat 113:791-833

Darlington PJ (1957) Zoogeography: the geographical distribution of animals. Wiley, New York

Diamond J (1975) The island dilemma: lessons of modern biogeographic studies for the design of nature reserves. Biol Conserv 7:129-146

Durrett R, Levin S (1996) Spatial models for species area curves. J Theor Biol 179:119-127

Dytham C (2003) Choosing and using statistics: a biologist's guide, 2nd edn. Blackwell, Oxford

Edinger EN, Jompa J, Limmon GV, Widjatmoko W, Risk MJ (1998) Reef degradation and coral biodiversity in Indonesia: effects of land-based pollution, destructive fishing practices and changes over time. Mar Pollut Bull 36: $617-630$

Gleason HA (1922) On the relation between species and area. Ecology 3:158-162

Gleason HA (1925) Species and area. Ecology 6:66-74

Hart DD, Horwitz RJ (1991) Habitat diversity and the species-area relationship: alternative models and tests. In: Bell SS, McCoy ED, Mushinsky HR (eds) Habitat structure: the physical arrangement of objects in space. Chapman \& Hall, London, p 47-68

Henderson PA, Seaby RMH (1999) Community analysis package. Version 1.33, PISCES Conservation, Lymington

Jackson JBC, Kirby MX, Berger WH, Bjorndal KA and 15 others (2001) Historical overfishing and the recent collapse of coastal ecosystems. Science 293:629-637

Lichstein JW, Simons TR, Shriner SA, Franzreb KE (2002) Spatial autocorrelation and autoregressive models in ecology. Ecol Monogr 72:445-463

Lomolino MV (2000) Ecology's most general, yet protean pattern: the species-area relationship. J Biogeogr 27: $17-26$

Lomolino MV, Weiser MD (2001) Towards a more general species-area relationship: diversity on all islands, great and small. J Biogeogr 28:431-445

MacArthur RH, Wilson EO (1967) The theory of island biogeography. Princeton University Press, Princeton, NJ

Editorial responsibility: Ronald Karlson (Contributing Editor), Newark, Delaware, USA
May RM (1975) Patterns of species abundance and diversity. In: Cody ML, Diamond JM (eds) Ecology and evolution of communities. Harvard University Press, Cambridge, MA, p 81-120

Neigel J (2003) Species-area relationships and marine conservation. Ecol Appl 13:138-145

Nilsson SG, Bengtsson J, As S (1988) Habitat diversity or area per se? Species richness of woody plants, carabid beetles and land snails on islands. J Anim Ecol 57:685-704

Palmer MW, Dixon PM (1990) Small scale environmental variability and the analysis of species distribution along gradients. J Veg Sci 1:57-65

Palmer MW, White PS (1994) Scale dependence and the species-area relationship. Am Nat 144(5):717-740

Peake AJ, Quinn GP (1993) Temporal variation in speciesarea curves for invertebrates in clumps of an intertidal mussel. Ecography 16:269-277

Pimm SL, Raven S (2000) Extinction by numbers. Nature 403: 843-845

Preston FW (1960) Time and space and the variation of species. Ecology 41:785-790

Preston FW (1962a) The canonical distribution of commonness and variation I. Ecology 43:185-215

Preston FW (1962b) The canonical distribution of commonness and variation II. Ecology 43:410-432

Roberts CM, Ormond RFG (1987) Habitat complexity and coral reef fish diversity and abundance on Red Sea fringing reefs. Mar Ecol Prog Ser 41:1-8

Rosenzweig ML (1995) Species diversity in space and time. Cambridge University Press, New York

Rosenzweig ML (1999) Heeding the warning in biodiversity's basic law. Science 284:276-277

Roth R (1976) Spatial heterogeneity and bird species diversity. Ecology 57:773-782

Simberloff DS (1976) Experimental zoogeography of islands: effects of island size. Ecology 57:629-648

Sale PF (1998) Appropriate spatial scales for studies of reef fish ecology. Aust J Ecol 23:202-208

Singh JS, Bourgeron P, Lauenroth WK (1996) Plant species richness and species-area relations in a shortgrass steppe in Colorado. J Veg Sci 7:645-650

ter Braak CJF (1987) Ordination. In: Jongman RH, ter Braak CJF, van Tongeren OFR (eds) Data analysis in community ecology. Pudoc, Wageningen, p 91-173

Whitmore TC, Sayer JA (1992) Tropical deforestation and species extinction. Chapman \& Hall, London

Whittaker RJ (1998) Island biogeography: ecology, evolution, and conservation. Oxford University Press, Oxford

Williams CB (1943) Area and number of species. Nature 152:264-267

Willis KJ, Whittaker RJ (2002) Species diversity-scale matters. Science 295:1245-1248

Submitted: April 16, 2006; Accepted: October 30, 2006

Proofs received from author(s): July 30, 2007 